\title{
Hydroxypropyl Methylcellulose Based Cephalexin Extended Release Tablets: Influence of Tablet Formulation, Hardness and Storage on in Vitro Release Kinetics
}

\author{
Muniyandy SARAVAnAN, ${ }^{* a}{ }^{, a}$ Kalakonda SRI NATARAJ, ${ }^{a}$ and Kettavarampalayam Swaminath GANESH ${ }^{b}$ \\ ${ }^{a}$ Department of Pharmaceutics, Vel's College of Pharmacy; Chennai-600117, India: and ${ }^{b}$ Shelys Pharmaceuticals \\ Limited; Dar es salaam, Tanzania. $\quad$ Received January 6, 2003; accepted May 12, 2003
}

The object of this study was to develop hydroxypropyl methylcellulose (HPMC) based cephalexin extended release tablet, which can release the drug for six hours in predetermined rate. Twenty-one batches of cephalexin tablets were prepared by changing various physical and chemical parameters, in order to get required theoretical release profile. The influences of HPMC, microcrystalline cellulose powder (MCCP), granulation technique, wetting agent and tablet hardness on cephalexin release from HPMC based extended release tablets were studied. The formulated tablets were also characterized by physical and chemical parameters. The dissolution results showed that a higher amount of HPMC in tablet composition resulted in reduced drug release. Addition of MCCP resulted in faster drug release. Tablets prepared by dry granulation was released the drug slowly than the same prepared with a wet granulation technique. Addition of wetting agent in the tablets prepared with dry granulation technique showed slower release. An increase in tablet hardness resulted in faster drug release. Tablets prepared with a wet granulation technique and having a composition of $9.3 \%$ w/w HPMC with a hardness of $10-12 \mathrm{~kg} / \mathrm{cm}^{2}$ gave predicted release for $6 \mathrm{~h}$. The in vitro release data was well fit in to Higuchi and Korsmeyer-Peppas model. Physical and chemical parameters of all formulated tablets were within acceptable limits. One batch among formulated twenty-one batches was successful and showed required theoretical release. The effect of storage on in vitro release and physicochemical parameters of successful batch was studied and was found to be in acceptable limits.

Key words cephalexin; extended release tablet; hydroxypropyl methylcellulose; tablet hardness; release kinetics

Cephalexin is a semi synthetic antibiotic derived from Cephalosporin ' $\mathrm{C}$ '. It is absorbed completely $(80-100 \%)$ after oral administration ${ }^{1)}$ and having a biological half-life ${ }^{2)}$ of $1 \mathrm{~h}$. To maintain therapeutic range, the drug should be administered 3-4 times a day, which leads to the saw tooth kinetic of the absorption and resulting in ineffective therapy. The conventional oral regimen results in initial high peak plasma level and that fall drastically below the effective concentration before the next dose. Hence, many authors attempted to develop sustained/extended release dosage forms for cephalexin in order to achieve constant effective plasma concentration. Shin and $\mathrm{Cho}^{3)}$ studied cephalexin release kinetics from Eudragit-hydroxypropyl cellulose membranes. Martinez-Pacheco et al. ${ }^{4,5)}$ formulated double-layer tablets containing small proportions of acrylic resins for cephalexincontrolled release and also studied the effect of compression force on biopharmaceutical characteristics of Eudragit RS-based cephalexin tablets. Schneider et al. ${ }^{6}$ evaluated cephalexin prolonged release formulation for better therapy. Dhopeshwarkar et al. . $^{7}$ developed cephalexin sustained release matrix tablet by using xanthan gum and sodium alginate.

In our previous work, we reported ${ }^{8)}$ Eudragit L100 based cephalexin tablet with ideal release profile. In the present study we attempted to formulate cephalexin extended release tablet by using hydroxypropyl methylcellulose (HPMC), which is economic and the drug release from HPMC matrix is uniform irrespective of the $\mathrm{pH}$. Since the solubility of HPMC is $\mathrm{pH}$ independent, constant release rate throughout the gastrointestinal tract can be expected from the HPMC based tablets than the Eudragit whose solubility is $\mathrm{pH}$ dependent. The influences of HPMC, microcrystalline cellulose (MCCP), method of granulation technique, wetting agent, hardness, and storage on in vitro release profile were studied to find out suitable tablet formulation with acceptable physical and chemical parameters. The tablets were characterized by drug content, weight variation, hardness, thickness, friability, and stability. The in vitro release of formulated extended release tablet was compared with a marketed sample.

Theory By considering pharmacokinetic parameters, we have calculated and reported ${ }^{8}$ theoretical release profile of cephalexin for an ideal tablet. Briefly, the tablet should release $125 \mathrm{mg}$ of cephalexin initially within first $1 \mathrm{~h}$ and $46.7 \mathrm{mg}$ of cephalexin per hour for next $5 \mathrm{~h}$ from $375 \mathrm{mg}$ of total dose in order to maintain plasma cephalexin concentration of $4.5 \mathrm{mg} / 1$. The percentage of drug to be released from an ideal tablet containing $375 \mathrm{mg}$ of cephalexin is given in Fig. 1.

\section{Experimental}

Materials Cephalexin IP was obtained from Orchid Chemicals and Pharmaceutical Ltd., India. Hydroxypropyl methylcellulose (Methocel $15 \mathrm{cps}$ ) was obtained from Dow chemicals India. Polyvinylpyrrolidine was purchased from Shanghai Sun Power New Material Company, China. Magnesium Stearate IP was procured from Sinai Pharma Pvt Ltd., India. Lactose IP was purchased from Lactose India Ltd. All other chemicals used were of analytical grade.

Preparation of Cephalexin Extended Release Tablets by Wet Granulation Technique The cephalexin extended release tablets (batches $1-5$ ) were prepared by wet granulation ${ }^{9)}$ technique. Ingredients required for 6000 tablets as per the formula given in Table 1 were weighed and granulated as follows. The drug and HPMC were separately passed through sieve \#40 and 60 , respectively and mixed with lactose, which was previously passed through sieve $\# 40$, in a double cone blender for $5 \mathrm{~min}$. After mixing the powders were transferred to 101 capacity rapid mixer granulator (Kevin engineers, India) and granulated for $3 \mathrm{~min}$ by using $10 \% \mathrm{w} / \mathrm{v}$ Polyvinylpyrrolidine (PVP) in isopropyl alcohol $(50 \% \mathrm{v} / \mathrm{v})$ as binding agent. The wet granules were passed through sieve $\# 18$ and dried at $40^{\circ} \mathrm{C}$ for $90 \mathrm{~min}$ in a tray 


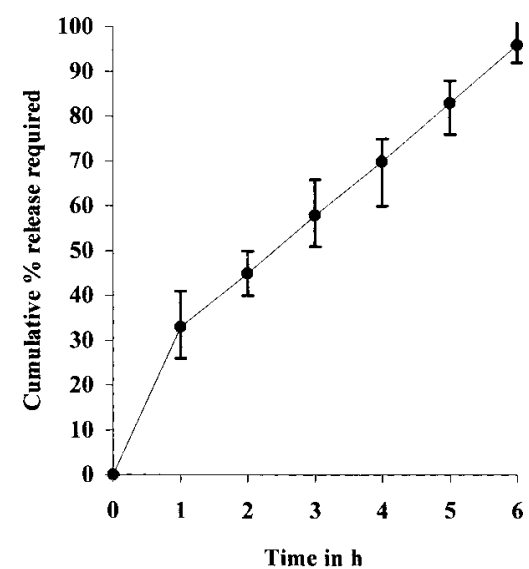

Fig. 1. Theoretical Release Profile of Ideal Extended Release Tablet Containing $375 \mathrm{mg}$ of Cephalexin and Intended to Maintain Effective Concentration for $6 \mathrm{~h}$

The bar indicates theoretical release limits.

drier (Bombay Engineering Works, India). The dried granules were passed through sieve \#14 and the moisture content was determined by Karl Fischer method (Karl-Fischer Titrator, Precision V/M MD, India). Then the dried granules were passed through sieve \#14, lubricated with magnesium stearate by mixing in rapid mixer granulator (Kevin Engineers, India) at slow speed for $5 \mathrm{~min}$ and compressed using 15/32 flat punches in Cadmach tablet compression machine to get tablets. Batches 1,2 and 5 were prepared by using different ratio of HPMC as per the formula given in Table 1. Batches 2, 3 and 4 were prepared with varying quantity of MCCP. To study the effect of hardness on release profile, in each batch, three sub-batches $\mathrm{A}, \mathrm{B}$ and $\mathrm{C}$ were prepared with a hardness of $6-8,8-10$ and $10-12 \mathrm{~kg} / \mathrm{cm}^{2}$, respectively.

Preparation of Cephalexin Extended Release Tablets by Dry Granulation Technique The granules required for batch 6 (6000 tablets) were prepared by dry granulation technique ${ }^{9)}$ as per the formula given in Table 1 . The drug and HPMC were separately passed through sieve \#40 and 60, respectively and mixed with lactose, which was previously passed through sieve \#40, in a double cone blender. The resulting mixture was compressed into slugs using $12.5 \mathrm{~mm}$ flat punches. The slugs thus obtained were crushed in Kalweka dry granulator, passed through sieve \#14 and the moisture content were measured (Karl-Fischer Titrator, Precision V/M MD, India). The ultimately obtained granules were lubricated with magnesium stearate by mixing in a rapid mixer granulator (Kevin Engineers, India) at slow speed for $5 \mathrm{~min}$ and were compressed to tablets by using $15 / 32$ flat punches.

Batch 7 was prepared with a wetting agent polysorbate 80 , in order to study its influence on the in vitro release. The tablets were prepared by the procedures similar to that of batch 6 . Polysorbate 80 was added to cephalexin/HPMC mixture in the double cone blender and mixed for $5 \mathrm{~min}$. Then the lactose was added and the tablets were prepared as described for batch 6 . To study the effect of hardness on release profile, in each batch three sub-batches A, B and C were prepared with hardness of $6-8,8-10$ and $10-12 \mathrm{~kg} / \mathrm{cm}^{2}$, respectively.

Physical Parameters The formulated tablets were tested ${ }^{9,10)}$ for weight variation, thickness, friability (Friability test apparatus, Indian Equipment Corporation) and hardness (DrSchleuniger Pharmatron).

Drug Content Twenty tablets were weighed and powdered. The quantity equivalent to $100 \mathrm{mg}$ of cephalexin was weighed accurately and taken in $100 \mathrm{ml}$ volumetric flask. Fifty milliliters of water was added, sonicated (Sonicator-Branson, SmithKline) for $5 \mathrm{~min}$, made up to $100 \mathrm{ml}$ with water, and filtered. Two milliliters of above solution was diluted to $100 \mathrm{ml}$ in a volumetric flask and the drug was determined at $261 \mathrm{~nm}^{5)}$ by using UV-visible spectrophotometer (Shimadzu UV-2201).

In Vitro Release Studies The in vitro release of cephalexin from formulated tablets was carried out in $0.1 \mathrm{~N} \mathrm{HCl}$ for $1 \mathrm{~h}$, and continued in $0.01 \mathrm{~N}$ $\mathrm{HCl}$ for another $1 \mathrm{~h}$ and finally in phosphate buffer $\mathrm{pH} 7.4$ for $4 \mathrm{~h}$. The studies were performed in USP dissolution apparatus 1 (Programmable tablet dissolution tester USP XXI and XXII, TDT 067, ELECTROLAB, India) at $37 \pm 2{ }^{\circ} \mathrm{C}$ and $100 \mathrm{rpm}$. Samples were taken at hourly interval and analysed for cephalexin content at $261 \mathrm{~nm}^{5}$ by using UV-visible spectrophotometer. The same procedure was followed to study the in vitro release of cephalexin from a marketed product.

Stability Studies The formulated cephalexin tablets, batch 2 which gave in vitro drug release complying the calculated limits, were kept for a short term accelerated stability study in high density polyethylene sealed cover at $40 \pm 2{ }^{\circ} \mathrm{C} / 75 \pm 5 \% \mathrm{RH}$ as per International Conference on Harmonization States $(\mathrm{ICH})$ guidelines. Samples were with-drawn for every month of storage and evaluated ${ }^{8)}$ for appearance, hardness, drug content, and dissolution.

Release Kinetics Data obtained from in vitro release studies were fitted to various kinetic equations. The kinetic models ${ }^{11)}$ used are zero order, first order and Higuchi equation. The following plots were made: $Q_{t} v s . t$ (zero order kinetic model); $\log \left(Q_{0}-Q_{t}\right) v s$. $t$ (first order kinetic model) and $Q_{t} v s$. square root of $t$ (Higuchi model). Where $Q_{t}$ is the amount of cephalexin released at time $t$ and $Q_{0}$ is the initial amount of cephalexin present in tablets. Further, to find out the mechanism of drug release, first $60 \%$ drug release was fitted in Korsmeyer-Peppas model:

$$
M_{t} / M_{\alpha}=k t^{n}
$$

where $M_{t} / M_{\alpha}$ is fraction of drug released at time $t, k$ is rate constant and $n$ is release exponent. The $n$ value is used to characterize different release mechanisms. $^{11)}$

\section{Results and Discussion}

An ideal extended release tablet should release the required quantity of drug with predetermined kinetics in order to maintain effective drug plasma concentration. To achieve this the tablet should be formulated in such a way to release the drug in a predetermined and reproducible manner. By considering the biopharmaceutic and pharmacokinetic profile of the drug, the required release from the tablet can be predetermined. ${ }^{8)}$ To achieve the predetermined release profile, various formulation factors like polymer/drug ratio, hardness and additives should be modified to get the required release. Ideally, the tablet should release the drug as per the predetermined rate even under storage conditions.

Cephalexin is effective in wide variety of infections because they have a broad spectrum and high therapeutic/toxic ratio. Cephalexin monohydrate ${ }^{2,12}$ is a white to cream crystalline solid with bitter taste and having molecular weight of 365.4 (347.4 for anhydrous). It is soluble in water ( $1 \mathrm{~g}$ in $100 \mathrm{ml}$ ) and in dilute aqueous alkaline solutions. It is very slightly soluble to practically insoluble in alcohol and other organic solvents. Cephalexin is sensitive to moisture, heat and light. Generally tablets, capsules and dry powders should be stored ${ }^{2)}$ between $15-30^{\circ} \mathrm{C}$, in a dry and cool place. Reconstituted suspensions ${ }^{2)}$ are stable for 7 to $14 \mathrm{~d}$ at between $2-8{ }^{\circ} \mathrm{C}$ and $6-15^{\circ} \mathrm{C}$. In hydrochloric acid buffer ( $\left.\mathrm{pH} 1.2\right)$, cephalexin lost $5 \%$ activity in $24 \mathrm{~h}$ at $37^{\circ} \mathrm{C}$ as compare to a $45 \%$ loss in phosphate buffer at $\mathrm{pH} 6.5 .^{13)}$ Cephalexin in serum was found to lose $10 \%, 50 \%, 75 \%$ activity respectively, after storage at $5^{\circ} \mathrm{C}, 25^{\circ} \mathrm{C}$ and $37^{\circ} \mathrm{C}$ for $48 \mathrm{~h} .{ }^{13,14)}$ The antibiotic retains activity well in serum and urine as no loss in activity was noted after storage at $-20^{\circ} \mathrm{C}$ for $14 \mathrm{~d}^{14)}$

Because of shorter biological half-life, cephalexin should be preferably given in extended release dosage forms. In our previous work, we have calculated and reported the required theoretical release profile of cephalexin ${ }^{8)}$ from tablets (Fig. 1) and formulated Eudragit L100 based cephalexin tablet with ideal characteristic. In the present work, we tried to develop HPMC based cephalexin tablets, which could release the drug in predetermined rate for $6 \mathrm{~h}$. Twenty-one batches were formulated by changing formulation parameters as per the formula given in Table 1, in order to study the effect on in vitro release kinetics and to find out the tablet formulation, 
Table 1. Composition of Cephalexin Extended Release Tablets

\begin{tabular}{|c|c|c|c|c|c|c|c|}
\hline \multirow{2}{*}{ Ingredients (mg/tablet) } & Batch 1 & Batch 2 & Batch 3 & Batch 4 & Batch 5 & Batch 6 & Batch 7 \\
\hline & \multicolumn{5}{|c|}{ Wet granulation } & \multicolumn{2}{|c|}{ Dry granulation } \\
\hline Cephalexin IP & 375 & 375 & 375 & 375 & 375 & 375 & 375 \\
\hline HPMC $15 \mathrm{cps}$ & 20 & 35 & 35 & 35 & 50 & 35 & 35 \\
\hline Lactose & 40 & 40 & 40 & 40 & 40 & 40 & 40 \\
\hline МCCP & & & 10 & 20 & & & \\
\hline Polysorbate 80 & & & & & & & 5 \\
\hline PVP & 7 & 7 & 7 & 7 & 7 & & \\
\hline Magnesium stearate & 5 & 5 & 5 & 5 & 5 & 5 & 5 \\
\hline Total weight & 447 & 462 & 472 & 482 & 477 & 455 & 460 \\
\hline$\%$ of HPMC to cephalexin & 5.3 & 9.3 & 9.3 & 9.3 & 13.3 & 9.3 & 9.3 \\
\hline$\%$ of MCCP to cephalexin & & & 2.7 & 5.3 & & & \\
\hline
\end{tabular}

In each batch three sub batches $\mathrm{A}, \mathrm{B}$ and $\mathrm{C}$ were prepared with hardness of $6-8,8-10$ and $10-12 \mathrm{~kg} / \mathrm{cm}^{2}$, respectively.

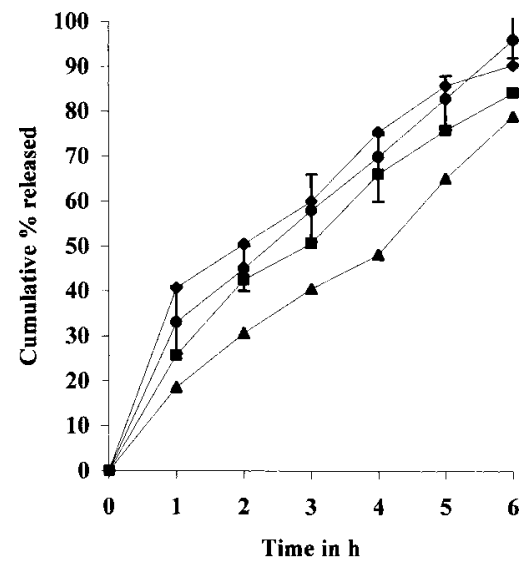

Fig. 2. Influence of HPMC on the in Vitro Release of Cephalexin from Formulated Tablets

The figure illustrates the cephalexin release from batch 1A $(-\square), 2 \mathrm{~A}(-\mathbf{-}-)$ and 5A (- - ) tablets formulated with 5.3, 9.3 and $13.3 \%$ of HPMC with respect to cephalexin and having a hardness of $6-8 \mathrm{~kg} / \mathrm{cm}^{2}$. The release is compared with theoretical release profile (- - Each data represents average of six readings and bar represents theoretical release limits.

which will give required release profile.

Batches 1,2 and 5 were formulated by using various cephalexin/HPMC proportions as per formula given in Table 1 , in order to study the effect of HPMC on drug release profile. Amount of percentage of polymer added in each batch is shown in Table1. Figure 2 shows the cephalexin cumulative percentage released versus time for tablets formulated with various percentage of HPMC. All the batches showed a release over $4-6 \mathrm{~h}$. As expected, the release rate was slower with higher quantity of HPMC, the tablets having $9.3 \%$ of HPMC with respect to drug showed optimum release profile as shown in Fig. 2. At higher percentage of HPMC in tablets, when in contact with release medium, HPMC may swell ${ }^{15,16}$ ) and form a thick gel, thus may decrease the size of the pores present in the tablet and reducing the drug release.

Using the same formula and changing the granulation technique batch 2 and 6 were formulated in order to find out the change in release kinetics. As shown in Fig. 3, tablets formulated by dry granulation released the drug slowly than the tablet formulated by wet granulation technique. This may be due to slow penetration of dissolution medium into the tablet prepared by dry granulation technique. The presence of more moisture in granules prepared by dry granulation technique

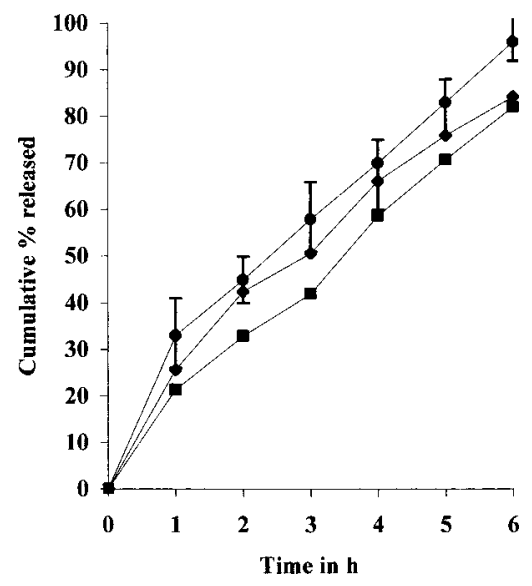

Fig. 3. Influence of Granulation Technique on the in Vitro Release of Cephalexin from Formulated Tablets

The figure illustrates the drug release from batch 2A ( - - ) and 6A (-口-), tablets formulated by wet and dry granulation, respectively and having a hardness of $6-8 \mathrm{~kg} / \mathrm{cm}^{2}$. The release is compared with theoretical release profile (- - Each data represents average of six readings and bar represents theoretical release limits.

(Table 2) resulted in the faster swelling of HPMC matrix, which might reduced the pore size through which diffusion of drug towards the dissolution medium ${ }^{15,16)}$ occurs and thus slower the release of drug. More over the presence of PVP, highly water soluble additive, in the tablets prepared by wet granulation technique, may undergo rapid dissolution which may favour penetration/contact of dissolution medium inside the swollen HPMC matrix/drug and thus may give faster release.

To study the influence of wetting agent on in vitro release profile in batch 7 , polysorbate 80 was added as wetting agent and its effect on in vitro release was studied. The influence of polysorbate 80 on the in vitro release of cephalexin from the formulated tablets is given Fig. 4. Theoretically, the addition of wetting agent, which enhances the contact of drug and dissolution medium, should result in faster dissolution. Nevertheless, as shown in Fig. 4, the presence of the wetting agent in the HPMC matrix tablet has reduced the drug release considerably. Addition of wetting agent in HPMC tablets will enhance the contact of polymer matrix with the dissolution medium, which in turn may produce rapid swelling of the tablet and thus produced slower release.

In batches 2, 3 and 4 the quantity of MCCP incorporated 


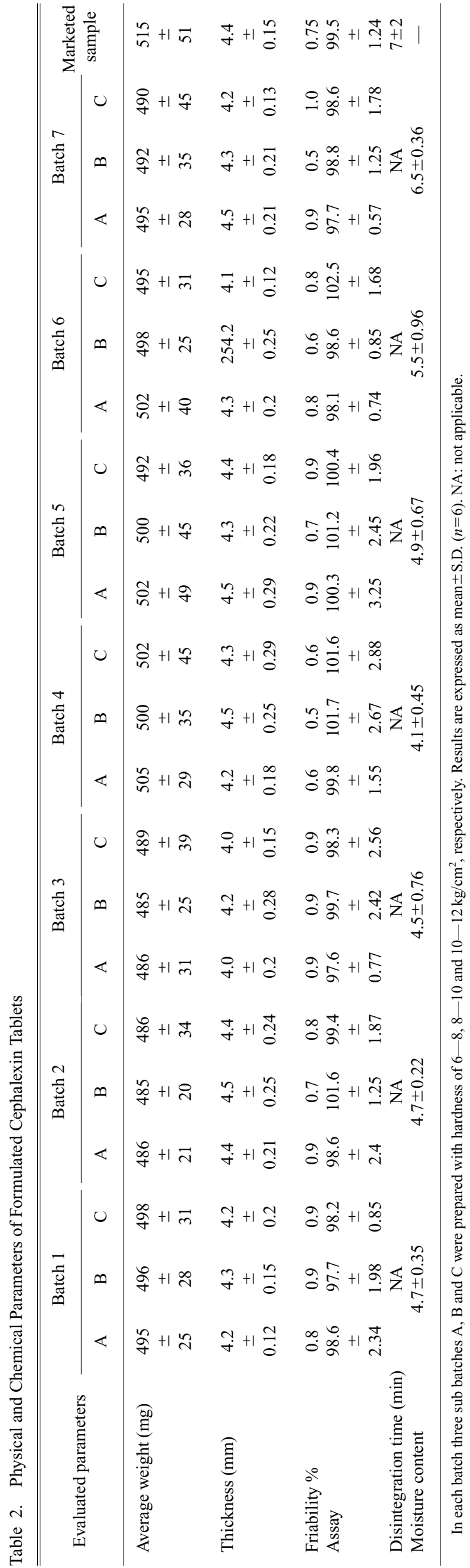

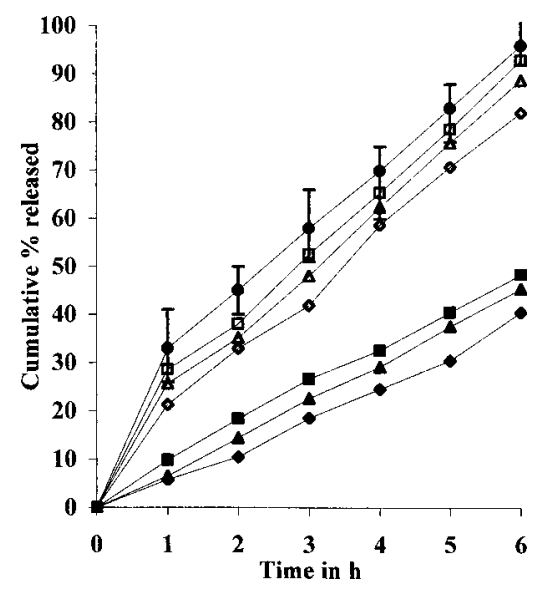

Fig. 4. Influence of Polysorbate 80 and Tablet Hardness on the in Vitro Release of Cephalexin from HPMC Tablets

The figure illustrates the drug release from batch $6 \mathrm{~A}(-\diamond-), 6 \mathrm{~B}(-\triangle-), 6 \mathrm{C}$ $(-\square-), 7 \mathrm{~A}(-\longrightarrow), 7 \mathrm{~B}(-\mathbf{\Delta}-)$ and 7C (- - - tablets. Sub batches A, B and C indicate a hardness of $6-8,8-10$ and $10-12 \mathrm{~kg} / \mathrm{cm}^{2}$, respectively. The release is compared with theoretical release profile (- - Each data represents average of six readings and bar represents theoretical release limits.

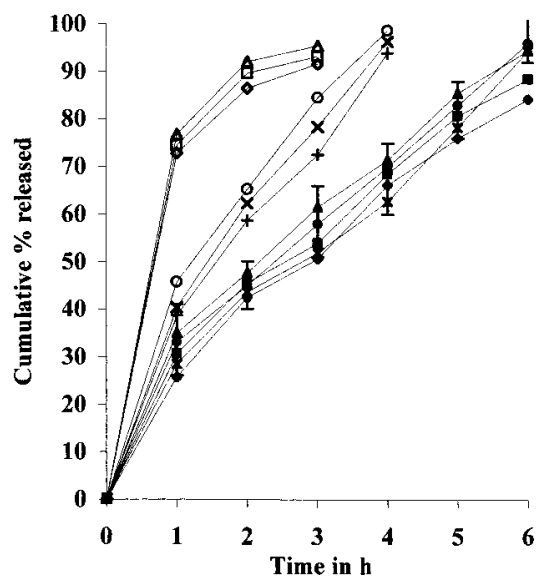

Fig. 5. Influence of Percentage of MCCP and Tablet Hardness on the in Vitro Release of Cephalexin from HPMC Tablets

The figure illustrates the drug release from batch $2 \mathrm{~A}(-\rightarrow), 2 \mathrm{~B}(-\mathbf{-}-), 2 \mathrm{C}$ $(-\mathbf{\Delta}-), 3 \mathrm{~A}(-+-), 3 \mathrm{~B}(-\times-), 3 \mathrm{C}(-\mathrm{O}-), 4 \mathrm{~A}(-\triangleright-), 4 \mathrm{~B}(-\square-)$ and $4 \mathrm{C}$ $(-\triangle-)$ tablets. Batch 2,3 and 4 were formulated with $0,2.65$ and $5.3 \%$ of MCCP with respect to cephalexin. Sub batches A, B and C indicate a hardness of $6-8,8-10$ and $10-12 \mathrm{~kg} / \mathrm{cm}^{2}$, respectively. The release is compared with theoretical release profile (- - ) and a marketed sample ( $*$ ). Each data represents average of six readings and bar represents theoretical release limits.

was varied, to find out its effect on the dissolution profile. In vitro release of cephalexin from tablet formulation made with different percentage of MCCP was given in Fig. 5. Incorporation of MCCP enhanced the drug release from the HPMC tablets. MCCP, in general, is used in tablet formulation as diluent and disintegrant. The disintegrant MCCP may disintegrate the hydrated layer, which is formed around the HPMC matrix when in contact with dissolution medium, thus may form pores/channels, thereby enhance the contact between drug and dissolution medium to give faster drug release. In all batches, three sub batches were prepared with different hardness (Table 1) in order to study its influence on in vitro release and to find out the suitable formulation, which can release the cephalexin in the predetermined rate. In general, increase in hardness in tablet will result in less porosity and slow drug release. As indicated in Figs. 4, 5 and 6 , the increase in hardness of tablets formulated with HPMC 
results in increased drug release. This may be due to faster swelling of HPMC in tablets having lower hardness and higher porosity. Tablets with low hardness swell immediately forming a gel like layer around the tablet and blocking the surface pores, resulting in slower drug release. Therefore, this is also a considerable factor in optimising drug release. Only batch 2 has showed required release profile among formulated seven batches and it is comparable with the release of a marketed formulation as shown in Fig. 5.

All other evaluation parameters like drug content, hardness, friability, weight variation, thickness and moisture content were studied for all the batches. All batches passed the acceptable limits of their respective parameters as shown in Table 2. The in vitro release data obtained were fitted in to

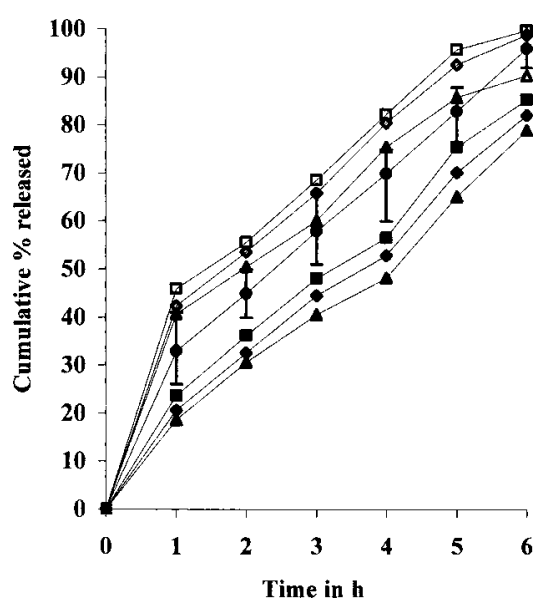

Fig. 6. Influence of Tablet Hardness on the in Vitro Release of Cephalexin from HPMC Tablets

The figure illustrates the drug release from batch $1 \mathrm{~A}(-\triangle-), 1 \mathrm{~B}(-\diamond-), 1 \mathrm{C}$ $(-\square-), 5 \mathrm{~A}(-\boldsymbol{\Delta}-), 5 \mathrm{~B}(--)$ and $5 \mathrm{C}(-\mathbf{-}-)$ tablets. Sub batches A, B and C indicate a hardness of $6-8,8-10$ and $10-12 \mathrm{~kg} / \mathrm{cm}^{2}$, respectively. The release is compared with theoretical release profile (- - Each data represents average of six readings and bar represents theoretical release limits. various kinetic equations. Correlations of individual batch with applied equation are given in Table 4 . The release rates were calculated from the slope of the appropriate plots. Batches 1, 2, 3 and 4 showed higher correlation with Higuchi plot than zero order and first order. Batches 5, 6, 7 showed higher correlation with zero order equation than Higuchi and first order. To find out release mechanism the in vitro release data were applied in Korsmeyer-Peppas equation. The release exponent $n$ was determined and given in Table 4. Batch 1 tablets formulated with 5.3 percentage of HPMC with respect to drug showed ( $n=0.28$ to 0.35 ) Fickian diffusion. Batches prepared with 9.3 and $13.3 \%$ of HPMC showed $(n=0.51$ to 0.7$)$ Anomalous (non-Fickian) diffusion. The tablet formulated with wetting agent (batch 7) showed ( $n=0.88$ to 1.20 ) super case-II diffusion principle.

Accelerated stability studies were performed on batch 2 tablets as per ICH guidelines. The cephalexin content and in vitro release were tested at periodic time intervals. The cephalexin contents were decreased periodically as shown in

Table 3. Physical and Chemical Parameters of Batch 2 Tablets during Stability Studies

\begin{tabular}{cllcc}
\hline \hline $\begin{array}{c}\text { Batch } \\
\text { No. }\end{array}$ & $\begin{array}{l}\text { Stability } \\
\text { duration }\end{array}$ & Appearance & $\begin{array}{c}\text { Hardness } \\
\left(\mathrm{kg} / \mathrm{cm}^{2}\right)\end{array}$ & \% Drug content \\
\hline \multirow{2}{*}{$2 \mathrm{~A}$} & Initial & Pale yellow & $6-8$ & $98.6 \pm 2.4$ \\
& After 30 d & Pale yellow & $3.5-5.5$ & $95.4 \pm 3.2$ \\
& After 60d & Pale yellow & $3-3.5$ & $91.8 \pm 1.9$ \\
& After 90d & Pale yellow & $2-3$ & $87.6 \pm 3.5$ \\
2B & Initial & Pale yellow & $8-10$ & $101.6 \pm 1.25$ \\
& After 30 d & Pale yellow & $6.5-7.5$ & $97.9 \pm 2.45$ \\
& After 60d & Pale yellow & $5-6$ & $90.5 \pm 2.88$ \\
& After 90d & Pale yellow & $4-5.5$ & $88.4 \pm 3.49$ \\
& Initial & Pale yellow & $10-12$ & $99.4 \pm 1.87$ \\
& After 30d & Pale yellow & $7.5-9.5$ & $96.5 \pm 2.33$ \\
& After 60d & Pale yellow & $7-9$ & $93.6 \pm 3.48$ \\
& After 90d & Pale yellow & $6-8$ & $90.7 \pm 2.4$ \\
\hline
\end{tabular}

Results are expressed as mean \pm S.D. $(n=6)$.

Table 4. Coefficient, in Vitro Release Rate and the Release Exponent of Cephalexin from Formulated Tablets

\begin{tabular}{|c|c|c|c|c|c|c|c|c|}
\hline \multirow{2}{*}{ Batch No. } & \multicolumn{2}{|c|}{ Zero order } & \multicolumn{2}{|c|}{ First order } & \multicolumn{2}{|c|}{ Higuchi } & \multicolumn{2}{|c|}{ Korsmeyer-Peppas } \\
\hline & $r^{2}$ & $k_{0}\left(\mathrm{~h}^{-1}\right)$ & $r^{2}$ & $k_{1}\left(\mathrm{~h}^{-1}\right)$ & $r^{2}$ & $k_{\mathrm{H}}\left(\mathrm{h}^{-1 / 2}\right)$ & $r^{2}$ & $n$ value \\
\hline $1 \mathrm{~A}$ & 0.9113 & 13.80 & 0.8866 & 0.0249 & 0.9924 & 37.03 & 0.9922 & 0.35 \\
\hline 1B & 0.9229 & 15.14 & 0.7159 & 0.0375 & 0.9948 & 40.40 & 1 & 0.34 \\
\hline $1 \mathrm{C}$ & 0.9067 & 15.21 & 0.6028 & 0.0479 & 0.9929 & 40.91 & 1 & 0.28 \\
\hline $2 \mathrm{~A}$ & 0.9663 & 13.47 & 0.9305 & 0.0211 & 0.9823 & 34.90 & 0.9854 & 0.63 \\
\hline $2 \mathrm{~B}$ & 0.9575 & 13.87 & 0.9000 & 0.0233 & 0.9874 & 36.22 & 0.9942 & 0.52 \\
\hline $2 \mathrm{C}$ & 0.9500 & 14.58 & 0.8374 & 0.0278 & 0.9920 & 38.30 & 0.9907 & 0.51 \\
\hline $3 \mathrm{~A}$ & 0.9636 & 22.19 & 0.8315 & 0.0274 & 0.9847 & 45.37 & 1 & 0.61 \\
\hline $3 \mathrm{~B}$ & 0.9598 & 23.10 & 0.7935 & 0.0306 & 0.9909 & 47.47 & 1 & 0.63 \\
\hline $3 \mathrm{C}$ & 0.9418 & 23.63 & 0.7142 & 0.0371 & 0.9969 & 49.17 & 1 & 0.52 \\
\hline $4 \mathrm{~A}$ & 0.7665 & 28.88 & 0.8866 & 0.0287 & 0.9496 & 55.10 & NA & NA \\
\hline 4B & 0.7607 & 29.48 & 0.9135 & 0.0261 & 0.9467 & 56.36 & NA & NA \\
\hline $4 \mathrm{C}$ & 0.7559 & 30.18 & 0.9223 & 0.0244 & 0.9441 & 57.81 & NA & NA \\
\hline $5 \mathrm{~A}$ & 0.9889 & 12.41 & 0.9456 & 0.0192 & 0.9301 & 30.94 & 0.9990 & 0.69 \\
\hline $5 \mathrm{~B}$ & 0.9901 & 13.07 & 0.9368 & 0.0203 & 0.9435 & 32.80 & 0.9989 & 0.69 \\
\hline $5 \mathrm{C}$ & 0.9840 & 13.58 & 0.9239 & 0.0218 & 0.9550 & 34.38 & 0.9990 & 0.64 \\
\hline $6 \mathrm{~A}$ & 0.9906 & 13.25 & 0.9410 & 0.0187 & 0.9458 & 33.28 & 0.9808 & 0.70 \\
\hline $6 \mathrm{~B}$ & 0.9873 & 14.07 & 0.9035 & 0.0233 & 0.9544 & 35.55 & 0.9723 & 0.63 \\
\hline $6 \mathrm{C}$ & 0.9818 & 14.51 & 0.8587 & 0.0263 & 0.9635 & 36.95 & 0.9666 & 0.54 \\
\hline $7 \mathrm{~A}$ & 0.9914 & 6.64 & 0.9940 & 0.0127 & 0.8710 & 15.98 & 0.9930 & 1.10 \\
\hline $7 \mathrm{~B}$ & 0.9991 & 7.63 & 0.9923 & 0.0132 & 0.9002 & 18.60 & 0.9989 & 1.08 \\
\hline $7 \mathrm{C}$ & 0.9963 & 7.89 & 0.9903 & 0.0136 & 0.9392 & 19.70 & 0.9990 & 0.88 \\
\hline
\end{tabular}



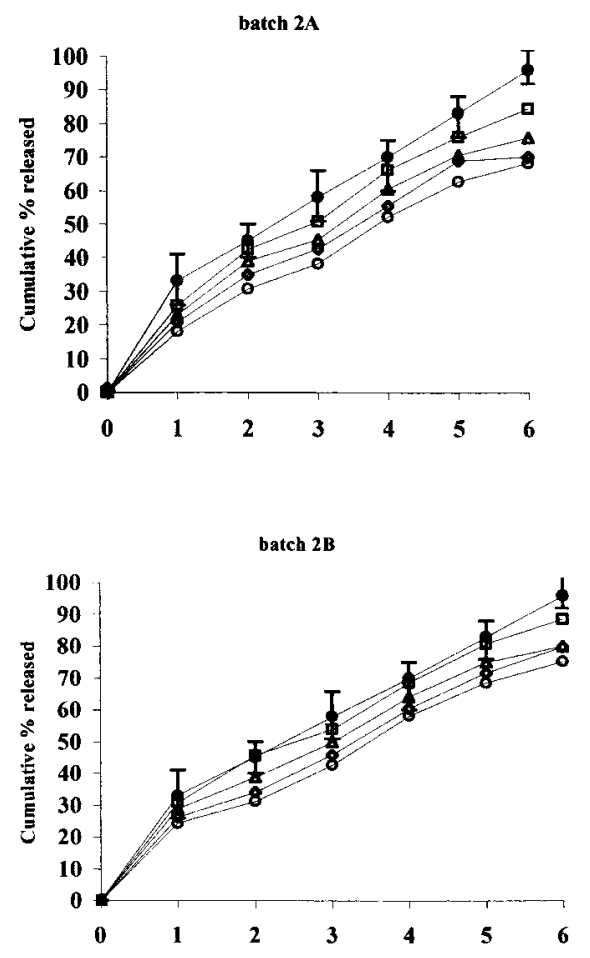

batch $2 \mathrm{C}$

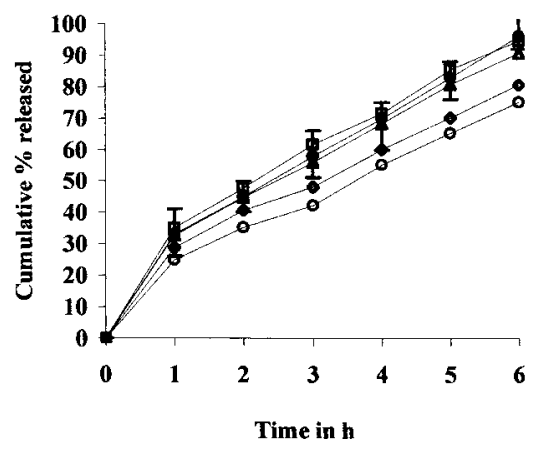

Fig. 7. The in Vitro Release Profile of Batch 2 during Stability Studies

Initial ( $-\square-$ ), first month $(-\triangle-)$, second month $(-\diamond-)$ and third month $(-\mathrm{O}-)$. The release is compared with theoretical release profile (- - ). Each data represents average of six readings and bar represents theoretical release limits.

Table 3, this may be due to the presence of moisture and heat. ${ }^{2,13,14)}$ The changes of in vitro release profile observed during stability studies are shown in Fig. 7. The drug release become slower on storage, this is because of decrease in hardness of the tablet, may be due to ageing of HPMC gel, as given in Table 3 . In vitro release from the batch $2 \mathrm{C}$ with the hardness of $10-12 \mathrm{~kg} / \mathrm{cm}^{2}$ was found to be within predicted release profile for longer time than the other batches. All other tested parameters of batch $2 \mathrm{C}$ were in acceptable limits
Table 5. Change in Coefficient, Release Rate Constant and Release Exponent during Stability Studies

\begin{tabular}{lccccc}
\hline \hline \multirow{2}{*}{$\begin{array}{c}\text { Batch No. } \\
\text { and period }\end{array}$} & \multicolumn{2}{c}{ Higuchi } & & \multicolumn{2}{c}{ Korsmeyer-Peppas } \\
\cline { 2 - 3 } \cline { 5 - 6 } & $r^{2}$ & $k_{\mathrm{H}}\left(\mathrm{h}^{-1 / 2}\right)$ & & $r^{2}$ & $n$ value \\
\hline $2 \mathrm{~A}_{\text {initial }}$ & 0.9823 & 34.90 & & 0.9854 & 0.63 \\
$2 \mathrm{~A}_{1 \text { month }}$ & 0.9790 & 31.84 & & 0.9932 & 0.67 \\
$2 \mathrm{~A}_{2 \text { month }}$ & 0.9706 & 30.13 & & 0.9906 & 0.69 \\
$2 \mathrm{~A}_{3 \text { month }}$ & 0.9616 & 28.64 & & 0.9942 & 0.74 \\
$2 \mathrm{~B}_{\text {initial }}$ & 0.9874 & 36.22 & & 0.9942 & 0.52 \\
$2 \mathrm{~B}_{1 \text { month }}$ & 0.9838 & 33.29 & & 0.9898 & 0.49 \\
$2 \mathrm{~B}_{2 \text { month }}$ & 0.9681 & 32.63 & & 0.9560 & 0.59 \\
$2 \mathrm{~B}_{3 \text { month }}$ & 0.9621 & 31.07 & & 0.9399 & 0.61 \\
$2 \mathrm{C}_{\text {initial }}$ & 0.9920 & 38.30 & & 0.9907 & 0.51 \\
$2 \mathrm{C}_{1 \text { month }}$ & 0.9884 & 36.499 & & 0.9973 & 0.49 \\
$2 \mathrm{C}_{2 \text { month }}$ & 0.9867 & 32.07 & & 0.9974 & 0.47 \\
$2 \mathrm{C}_{3 \text { month }}$ & 0.9753 & 30.016 & & 0.982 & 0.56 \\
\hline
\end{tabular}

as given in Table 3 and only this batch among formulated twenty one batches, was found to the suitable formulation for cephalexin extended release tablet. The in vitro release data obtained during stability studies were fitted to Higuchi and Peppas model to find out the change in release rate and mechanism. The correlation coefficients and $n$ value of tested batches remain nearly the same during stability studies as shown in Table 5. No change in release mechanism was observed, but the release rate constants were decreased as given in Table 5.

\section{References}

1) Thornhill T. S., Levison M. E., Johnson W. E., Kaye D., Applied Microbiology, 17, 457-461 (1969).

2) Colin Dollery (ed.), "Therapeutic Drugs," 2nd ed., Churchill Livingstone, Edinburgh, 1999, pp. c144-c146.

3) Shin S. C., Cho S. J., Drug Dev. Ind. Pharm., 22, 299-305 (1996).

4) Martinez-Pacheco R., Vila-Jato J. L., Concherio A., Souto C., Ramos T., Int. J. Pharmaceut., 47, 37-42 (1988).

5) Martinez-Pacheco R., Vila-Jato J. L., Souto C., Ramos T., Int. J. Pharmaceut., 32, 99-102 (1986).

6) Schneider H., Nightingale C. H., Quintiliani R., Flanagan D. R., $J$. Pharm. Sci., 67, 1620-1622 (1978).

7) Dhopeshwarkar V., O'Keefe J. C., Zatz J. L., Deeter R., Horton M., Drug Dev. Ind. Pharm., 20, 1851-1867 (1994).

8) Saravanan M., Nataraj K. S., Ganesh K. S., Biol. Pharm. Bull., 25, $541-545$ (2002).

9) Banker G. S., Anderson N. R., "Theory and Practice of Industrial Pharmacy," 3rd ed., ed. by Lachman L., Lieberman H. A., Kanig J. L., Varghese Publishing House, Mumbai, 1987, pp. 296-329.

10) United States Pharmacopoeia 23, United States Pharmacopoeial Convention, INC., 1995 , p. 323.

11) Costa P., Sousa Lobo J. M., E. J. Pharm. Sci., 13, 123-133 (2001).

12) Nichols W. K., "Anti-infectives, in Remington: The Science and Practice of Pharmacy," 19th ed., ed. by Gennaro A. R., Mack Publishing Company, Pennsylvania, 1995, pp. 1290-1297.

13) Simmons R. J., Anal. Microbiology, II, 193-195 (1972).

14) Wick W. E., Applied Microbiology, 15, 765-766 (1967).

15) Mitchell K., Ford J. L., Int. J. Pharmaceut., 100, 175-179 (1993).

16) Meury G. P., J. Pharm. Sci., 85, 725-731 (1996). 